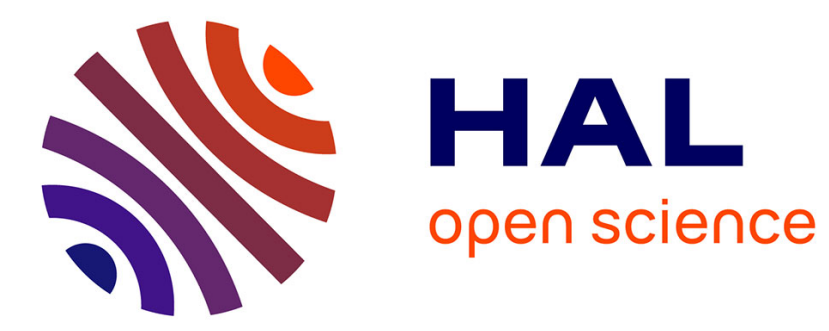

\title{
Kinetics of High Temperature Oxidation and Chromia Volatilization for a Binary $\mathrm{Ni}-\mathrm{Cr}$ Alloy
}

P. Berthod

\section{To cite this version:}

P. Berthod. Kinetics of High Temperature Oxidation and Chromia Volatilization for a Binary Ni-Cr Alloy. Oxidation of Metals, 2005, 64 (3-4), pp.235-252. 10.1007/s11085-005-6562-8 . hal-02181299

\section{HAL Id: hal-02181299 \\ https://hal.science/hal-02181299}

Submitted on 12 Jul 2019

HAL is a multi-disciplinary open access archive for the deposit and dissemination of scientific research documents, whether they are published or not. The documents may come from teaching and research institutions in France or abroad, or from public or private research centers.
L'archive ouverte pluridisciplinaire HAL, est destinée au dépôt et à la diffusion de documents scientifiques de niveau recherche, publiés ou non, émanant des établissements d'enseignement et de recherche français ou étrangers, des laboratoires publics ou privés. 


\section{Kinetics of High Temperature Oxidation and Chromia Volatilization for a Binary Ni-Cr Alloy}

\section{P. Berthod}

Laboratoire de Chimie du Solide Minéral (UMR 7555), Université Henri Poincaré Nancy 1

BP 239, 54506 Vandoeuvre-lès-Nancy - France

E-mail : patrice.berthod@centraliens-lille.org

The volatilization of the external chromia layer formed by oxidation of a Ni-30Cr alloy was studied at 1000, 1100,1200 and $1300^{\circ} \mathrm{C}$. This was done by analyzing the mass gain curves obtained by thermogravimetry on the basis of the differential equation that describes the oxidation kinetic, taking into account at each step the loss of $\mathrm{Cr}_{2} \mathrm{O}_{3}$ oxidized again into gaseous $\mathrm{CrO}_{3}$. The quantification of the parabolic constant and the volatilization constant was done by drawing $\mathrm{m} . \frac{\mathrm{dm}}{\mathrm{dt}}=\mathrm{Kp}-\mathrm{Kv} . \mathrm{m}$. This led to the values of both Kp and Kv for the four tested temperatures. These were compared to chromium balance sheets obtained by measuring the thicknesses of the chromia layer and chromium depletion in the alloy. A good agreement was found between the two methods. They both follow an Arrhenius law and precise values of the two constants are provided.

KEY WORDS: Nickel alloys; High temperature oxidation

Post-print version of the article Oxidation of Metals, Vol. 64, Nos. 3/4, pp. 235-252 (October 2005); DOI: 10.1007/s11085-005-6562-8

\section{INTRODUCTION}

When exposed to air at high temperature, chromium-containing alloys are covered by an external $\mathrm{Cr}_{2} \mathrm{O}_{3}$ layer which protects them against rapid oxidation (Ref. 1). Indeed, the progress of oxidation is then controlled by outwards $\mathrm{Cr}$ cation diffusion (or inwards oxygen anion diffusion) through this existing chromia scale. $\mathrm{Cr}_{2} \mathrm{O}_{3}$ is a stoechiometric oxide, therefore this diffusion is particularly low. Thus, chromia acts as an efficient protective barrier against oxidation and this element is often used to allow the superalloys to resist oxidation as well as other types of high temperature corrosion. For instance, it is the case in molten glasses in which chromium allows the formation by passivation of a protective barrier of chromia (Ref. 2 to 3 ), the dissolution of which is more limited in molten glass than alumina or $\mathrm{SiO}_{2}$ scales.

Unlike $\mathrm{Al}_{2} \mathrm{O}_{3}$, which develops on the external surface of alumina-forming alloys when oxidized at high temperature, chromia is not stable when the exposition temperature is too high. Indeed, when temperature exceeds $1000^{\circ} \mathrm{C}$, the chromia oxide suffers from a volatilization phenomenon. The external part of the $\mathrm{Cr}_{2} \mathrm{O}_{3}$ scale is continuously oxidized again into $\mathrm{CrO}_{3}$, a new oxide that is volatile and leaves the scale in a gaseous form. This phenomenon can become problematical at very high temperatures, in aeronautics (Ref. 4 to 5) as well as in other fields where chromia-forming alloys are used, such as Solid Oxide Fuel Cells (SOFCs), as demonstrated in recent works (Ref. 6 to 7).

The rate of chromia volatilization is negligible bellow $1000^{\circ} \mathrm{C}$ but increases with temperature and must be taken into account for very high temperatures. If not, determination of the parabolic constants by thermogravimetry becomes more difficult and leads to values that are too low to represent correctly the real damage caused by oxidation of the alloy. To better predict the lifetime of chromia-forming superalloys at very high temperatures, it could be necessary to state the rates of both mass gain kinetic and chromia volatilization. For temperatures up to $1000^{\circ} \mathrm{C}$, the oxidation kinetics follow, each time, the Wagner's law (1) which can be integrated into equation (2) for cases where the transient initial oxidation stages can be neglected compared to the following parabolic oxidation:

$$
\frac{\mathrm{dm}}{\mathrm{dt}}=\frac{\mathrm{Kp}}{\mathrm{m}} \quad \text { (1) } \quad \mathrm{m}=\sqrt{2 \cdot \mathrm{Kp}} \cdot \mathrm{t}^{\frac{1}{2}}
$$


where $\mathrm{m}$ is the mass gain per unit surface area induced by $\mathrm{Cr}_{2} \mathrm{O}_{3}$ formation (i.e. the mass of oxygen that joined the alloy), $\mathrm{Kp}$ is the parabolic oxidation rate constant and the time, the origin of which is the beginning of the oxidation phenomenon at the considered temperature. For higher temperature one must also estimate the linear speed of volatilization of chromia, i.e. the volatilization constant $\mathrm{Kv}$ which appears in the equations (3) and (4):

$$
\frac{\mathrm{dm}_{\mathrm{v}}}{\mathrm{dt}}=\mathrm{Kv} \quad \text { (3) } \quad \mathrm{m}_{\mathrm{v}}=\mathrm{Kv} . \mathrm{t}
$$

where $\mathrm{m}_{\mathrm{v}}$ is the mass of chromia that left the alloy per unit surface area in the $\mathrm{CrO}_{3}$ gaseous form.

Studies concerning chromia volatilization at high temperature began about fifty years ago, relating to its thermodynamic aspects as well as to its rate (Ref. 8 to 11). Relating to the kinetic of chromia volatilization, studies were done using thermogravimetry on iodide chromium, pure chromium, chromia-forming steels or sintered chromia, in different gas mixtures containing oxygen at different pressures. Thus numerous data about the chromia volatilization rate are already available. But it can be also interesting to directly determinate the volatilization constant from the thermogravimetry results obtained on complex superalloys, since volatilization of chromia may depend on the alloy. Indeed, knowing how it varies with the chemical composition of the alloy, or with its microstructure, allows to know how to modify this one in order to minimize chromia volatilization, and therefore to improve its protection against high temperature oxidation.

Several techniques are possible. For example thermogravimetric curves can be fitted by calculations on an equation model such as done by Di Martino (Ref. 12) on chromia-forming cobalt-base superalloys. Thanks to the Origin software, he automatically tested successive values of $\mathrm{Kv}$ until the theoretic curve based on the equation (5) converged to the experimental mass gain curve.

$$
\mathrm{m}=\sqrt{2 \cdot \mathrm{Kp}} \cdot \mathrm{t}^{\frac{1}{2}}-\mathrm{Kv} \cdot \mathrm{t}
$$

Here another technique was tested and applied to reach more directly the values of both $\mathrm{Kp}$ and $\mathrm{Kv}$. This will be done by analyzing the data files issued from the thermobalance according to the differential equation (22). A simple alloy was studied here, a Ni-30Cr binary alloy, the solidus temperature of which is high enough to allow test temperatures as high as $1300^{\circ} \mathrm{C}$ without risk of beginning of fusion. It contains a sole element able to promote a selective oxidation, while the other one is the base element of most chromiaforming superalloys used at very high temperatures.

\section{EXPERIMENTAL METHOD}

\section{Synthesis of the Samples and Oxidation Tests}

This $\mathrm{Ni}-30 \%_{\mathrm{w}} \mathrm{Cr}$ alloy was synthesized by foundry under controlled atmosphere (400mbar of pure Argon, $\mathrm{H}_{2} \mathrm{O}<3 \mathrm{ppm}, \mathrm{O}_{2}<2 \mathrm{ppm}, \mathrm{C}_{\mathrm{n}} \mathrm{H}_{\mathrm{m}}<0.5 \mathrm{ppm}$ ). The ingot of about $100 \mathrm{~g}$ was obtained from pure $\mathrm{Ni}$ and $\mathrm{Cr}$ (>99.9\% , Alfa Aesar) by induction melting in a copper crucible cooled by water circulation, in which it quickly solidified. Thereafter a treatment of about 2 hours at $1000^{\circ} \mathrm{C}$, followed by a slow cooling in furnace, was applied to release the stresses that can appear during the solidification. Parallelepipeds (dimensions of about $2 \mathrm{~mm} \times 10 \mathrm{~mm} \times 10 \mathrm{~mm}$ ) were cut to obtain the samples for the thermogravimetry tests. Their surfaces were polished with $\mathrm{SiC}$ paper from 80 to 1200 grid under water.

Oxidation tests were performed at high temperatures using a Setaram TGA92 thermobalance under a dry industrial air flow $\left(80 \% \mathrm{~N}_{2}-20 \% \mathrm{O}_{2}\right)$ at 1.5 liter/hour (corresponding to a linear flow rate of about $5 \mathrm{~cm} / \mathrm{min}$ ). Oxidation exposures were performed during 50 hours at $1000^{\circ} \mathrm{C}, 1100^{\circ} \mathrm{C}, 1200^{\circ} \mathrm{C}$ and $1300^{\circ} \mathrm{C}$. This duration is short enough to avoid the local detachments of the chromia scale that can affect the mass gain curves after 70-75 hours for such alloys, as well as their local consequences for the sub-surface microstructure. But this duration is also long enough to get a sufficiently long parabolic oxidation stage after the initial transient oxidation. The heating and cooling rates were respectively $20^{\circ} \mathrm{C} / \mathrm{min}$ and $10^{\circ} \mathrm{C} / \mathrm{min}$. The sum of the heating and cooling durations was about 3 hours, as is to say $5 \%$ of the whole test duration. The initial 
temperature was nearly $20^{\circ} \mathrm{C}$ (i.e. $293 \mathrm{~K}$ ) for all tests since the thermobalance was in an air-conditioned room at this temperature.

\section{Metallographic Study}

After oxidation tests all samples were covered with gold using cathodic evaporation, to give a good electrical conductivity to the external oxide layer. Thereafter the external oxide scale was strengthened by an electrolytic deposition of nickel. The samples were cut in two parts using an Accutom-2 saw equipped with a diamond blade. Afterwards they were embedded in a cold resin (Araldite CY230 +Strengthener Escil HY956), and polished, first with $\mathrm{SiC}$ paper from 80 to 1200 grid under water, then finished with diamond pastes $6 \mu \mathrm{m}$ and $3 \mu \mathrm{m}$ (DP-Suspension P of Struers).

The samples were observed using an optical microscope to observe the oxidation front of the samples. The thickness of the chromia scale, where it was not lost during cooling after test, was estimated by calculating the average value of about 20 measures performed using a graduated ocular. The interval of uncertainty was defined by the standard deviation.

The samples were also examined using a Scanning Electron Microscope (SEM) Philips XL30 in Back Scattered Electrons mode under a 20kV acceleration voltage. The Energy Dispersive Spectrometry (EDS) device was used to verify the real chemical composition of the obtained alloy and to analyze the external oxide scale.

Moreover, two chromium profiles were performed on each sample (i.e. for each temperature) by Wavelength Dispersion Spectrometry (WDS) using a Cameca SX100 microprobe, in order to estimate the total oxidized chromium. Depth and step of measures depended on the total depth of chromium depletion. The difference between, on the one hand the chromium quantity that left the metallic state, and on the other hand the chromium remaining on the sample as a $\mathrm{Cr}_{2} \mathrm{O}_{3}$ oxide, led to estimate by a metallographic way the quantity of volatilized chromium with the form $\mathrm{CrO}_{3}$. This was afterwards compared to the value that was mathematically determined from the thermogravimetry results.

\section{Mathematical Processing (transient oxidation)}

Before they reached the targeted test temperature, samples encountered a first oxidation during heating. Thereafter, the transient oxidation can be not finished, as shown by the existence of a first linear mass gain before the parabolic or pseudo-parabolic oxidation took place. Indeed, except for $1300^{\circ} \mathrm{C}$, all the mass gain curves obtained showed a more or less long initial linear part (of the $m=K_{1} . t$ type). This first double contribution of the preliminary oxidation to the mass gain must be taken into account.

Oxidation of such nickel alloys usually starts with nucleation and growth of both $\mathrm{NiO}$ and $\mathrm{Cr}_{2} \mathrm{O}_{3}$, and this transient stage finishes when the $\mathrm{Cr}_{2} \mathrm{O}_{3}$ scale becomes continuous. It is assumed here that the oxide formed during the transient oxidation stage is mainly of $\mathrm{Cr}_{2} \mathrm{O}_{3}$ since no $\mathrm{NiO}$ was detected in the parts of external oxide that remained on surface after test, like it will be seen further. Then it is considered here that the total mass gain that results from the transient oxidation stage is essentially due to $\mathrm{Cr}_{2} \mathrm{O}_{3}$.

The mathematical treatment of the mass curves was started by the determination of the contribution of the transient oxidation to the mass gain. First the recorded files were processed using the Excel 97 software of Microsoft to draw the mass gain curves $\mathrm{m}=\mathrm{f}(\mathrm{t})$, where $\mathrm{m}$ is counted from the time when the temperature reached the stage temperature $(\mathrm{t}=0)$.

The first mass gain induced by oxidation during heating and linear isothermal oxidation is the sum of an Heating part and a Linear part (6):

$$
\mathrm{m}_{0}=\mathrm{m}_{\mathrm{H}}+\mathrm{m}_{\mathrm{L}}
$$

Then the value of $K_{1}$, can be easily determined from the mass gain measured between the beginning of the isothermal stage and the beginning of the parabolic part of the curve. $\mathrm{m}_{\mathrm{H}}$ was determined from the $\mathrm{K}_{1}=\mathrm{f}(\mathrm{T})$ evolution given by the four values of $\mathrm{K}_{1}$ at $1273,1373,1473$ and $1573 \mathrm{~K}$ that led to a linear curve $\ln \left(\mathrm{K}_{\mathrm{l}}\right)$ versus $1 / \mathrm{T}\left(\mathrm{K}^{-1}\right)$. The Arrhenius constants $\left(\mathrm{K}_{\mathrm{lo}}\right.$ and $\left.\mathrm{Q}\right)$ that appear in equation (7) were determined. An estimated value of $m_{H}$ was obtained with the expression (8) calculated from the Riemann's sum (9) : 


$$
\mathrm{K}_{1}=\mathrm{K}_{\mathrm{lo}} \cdot \mathrm{e}^{\frac{-\mathrm{Q}}{\mathrm{R} \cdot \mathrm{T}}} \text { (7) } \quad \mathrm{m}_{\mathrm{H}}=\mathrm{K}_{\mathrm{l}_{\mathrm{o}}} \cdot \int_{0}^{\mathrm{t}_{\mathrm{H}}} \mathrm{e}^{\frac{-\mathrm{Q}}{\mathrm{R} \cdot \mathrm{T}(\mathrm{t})}} \cdot \mathrm{dt}(8) \quad \mathrm{m}_{\mathrm{H}}=\mathrm{K}_{\mathrm{l}_{\mathrm{o}}} \cdot\left(\sum_{\mathrm{n}=1}^{\mathrm{N}} \mathrm{e}^{\frac{-\mathrm{Q}}{\mathrm{R} \cdot\left(293 \mathrm{~K}+\mathrm{R}_{\mathrm{H}} \cdot \mathrm{n} \cdot \Delta \mathrm{t}\right)}}\right) \cdot \Delta \mathrm{t}
$$

where $293 \mathrm{~K}$ is the initial temperature, $\mathrm{R}_{\mathrm{H}}$ the heating rate, $\mathrm{t}_{\mathrm{H}}$ the heating duration, $\Delta \mathrm{t}$ the recording time increment (40s), and $N$ the approximate number of recording paths during the heating $N \cong \frac{t_{H}}{\Delta t}=\frac{T_{\text {test }}-293 K}{R_{H} \cdot \Delta t}$.

\section{Mathematical Processing (determination of Kp and Kv)}

When the temperature is not high enough to lead to a significant volatilization of chromia (e.g. $1000^{\circ} \mathrm{C}$ and less), the Wagner's law can be written (10). This means that the elementary mass gain between $t$ and $t+d t$ is proportional to the ratio of a constant by the existing mass gain, multiplied by the elementary time step dt. The existing mass gain is itself proportional to the oxide thickness and includes the mass gain $\mathrm{m}_{\mathrm{o}}$ previously obtained during the transient oxidation. These elementary mass gain and existing mass gain are both masses of oxygen that went on the alloy and formed the chromia oxide.

$$
\mathrm{m}=\frac{\mathrm{Kp}}{\mathrm{m}} \cdot \mathrm{dt}
$$

When the temperature is significantly higher than $1000^{\circ} \mathrm{C}$, the elementary mass loss by volatilization of chromia, which cannot be neglected, is proportional to the elementary time step dt, then equal to - Kv.dt. This loss of chromia is the sum of a loss of chromium $-\mathrm{Kv}_{\mathrm{Cr}}$. dt and a loss of oxygen $-\mathrm{Kv}_{\mathrm{O}}$.dt. The three losses are bound from one another by equations (11), (12) and (13).

$$
\mathrm{Kv}=\mathrm{Kv}_{\mathrm{Cr}}+\mathrm{Kv}_{\mathrm{O}} \quad \text { (11) } \quad \mathrm{Kv}_{\mathrm{Cr}}=\frac{2 \mathrm{M}_{\mathrm{Cr}}}{\mathrm{M}_{\mathrm{Cr} 2 \mathrm{O} 3}} \cdot \mathrm{Kv}=0.684 \mathrm{Kv} \quad \text { (12) } \quad \mathrm{Kv}_{\mathrm{o}}=\frac{3 \mathrm{M}_{\mathrm{O}}}{\mathrm{M}_{\mathrm{Cr} 2 \mathrm{O} 3}} \cdot \mathrm{Kv}=0.316 \mathrm{Kv}
$$

The elementary mass gain of oxygen, $\mathrm{dm}_{\mathrm{O}}$, is then the sum, on the one hand of a part proportional to the ratio of a constant which can be noted $\mathrm{Kp}_{\mathrm{O}}$ by the existing mass of oxygen $\mathrm{m}_{\mathrm{O}}$ multiplied by the elementary time step $\mathrm{dt}$, and on the other hand of the negative part $-\mathrm{Kv}_{\mathrm{O}}$.dt. Thus, the oxygen mass gain per unit surface area is given by (14). This equation can also become (15).

$$
\mathrm{dm}_{\mathrm{O}}=\frac{\mathrm{Kp_{ \textrm {O } }}}{\mathrm{m}_{\mathrm{O}}} \cdot \mathrm{dt}-\mathrm{Kv}_{\mathrm{O}} \cdot \mathrm{dt}
$$

$$
\mathrm{m}_{\mathrm{O}} \cdot \frac{\mathrm{dm}_{\mathrm{O}}}{\mathrm{dt}}=\mathrm{Kp}_{\mathrm{O}}-\mathrm{Kv}_{\mathrm{O}} \cdot \mathrm{m}_{\mathrm{O}}
$$

Unfortunately, because of the chromia volatilization the real value of $m_{O}$ cannot be directly measured during a thermogravimetry test. Indeed, at all times, the elementary mass gain $\mathrm{dm}$ or the measured mass gain $\mathrm{m}$ are lower than respectively $\mathrm{dm}_{\mathrm{O}}(16)$ and $\mathrm{m}_{\mathrm{O}}(17)$ and the difference increases with temperature. Equations (14) and (15) must be rewritten into (18) and (19) where $\mathrm{dm}$ and $\mathrm{Kv}$ appear instead of $\mathrm{dm}_{\mathrm{O}}$ and $\mathrm{Kv}_{\mathrm{O}} \mathrm{while}_{\mathrm{O}}$ must remain under $\mathrm{Kp}$.

$$
\begin{aligned}
& \mathrm{dm}=\mathrm{dm}_{\mathrm{O}}-\mathrm{Kv}_{\mathrm{Cr}} \cdot \mathrm{dt} \\
& \mathrm{dm}=\frac{\mathrm{Kp}_{\mathrm{O}}}{\mathrm{m}_{\mathrm{O}}} \cdot \mathrm{dt}-\mathrm{Kv} \cdot \mathrm{dt}
\end{aligned}
$$

$$
\begin{aligned}
& \mathrm{m}=\mathrm{m}_{\mathrm{O}}-\varepsilon \\
& \mathrm{m} \cdot \frac{\mathrm{dm}}{\mathrm{dt}}=\frac{\mathrm{m}}{\mathrm{m}_{\mathrm{O}}} \cdot \mathrm{Kp}_{\mathrm{O}}-\mathrm{Kv} \cdot \mathrm{m}
\end{aligned}
$$

During the test, $\mathrm{m}$ and $\mathrm{m}_{\mathrm{O}}$ increase simultaneously but not with the same rate at all times. Indeed, the mass gain is particularly fast during the first part of the parabolic oxidation (about the first 10 hours). But if thereafter the ratio $\frac{\mathrm{m}}{\mathrm{m}_{\mathrm{O}}}$, that can be written $1-\frac{\varepsilon}{\mathrm{m}_{\mathrm{O}}}$ in $(20)$, is assumed to be almost constant, the first member of equation (19) or (20) appears to vary linearly with $\mathrm{m}$. Drawing this quantity versus m may lead to a straight line, for what the ordinate at the origin is $\left(1-\frac{\varepsilon}{\mathrm{m}_{\mathrm{O}}}\right) . \mathrm{Kp}_{\mathrm{O}}$ which can be simply noted $\mathrm{Kp}(21)$, and the slope is $\mathrm{Kv}$. Then, plotting $\mathrm{m} \cdot \frac{\mathrm{dm}}{\mathrm{dt}}$ as a function of $\mathrm{m}$ theoretically may lead to the values of both $\mathrm{Kp}$ and $\mathrm{Kv}(22)$. 


$$
\begin{aligned}
& \mathrm{m} \cdot \frac{\mathrm{dm}}{\mathrm{dt}}=\left(1-\frac{\varepsilon}{\mathrm{m}_{\mathrm{O}}}\right) \cdot \mathrm{Kp}_{\mathrm{O}}-\mathrm{Kv} \cdot \mathrm{m} \\
& \mathrm{m} \cdot \frac{\mathrm{dm}}{\mathrm{dt}}=\mathrm{Kp}-\mathrm{Kv} \cdot \mathrm{m}
\end{aligned}
$$

$$
\mathrm{Kp}=\left(1-\frac{\varepsilon}{\mathrm{m}_{\mathrm{O}}}\right) \cdot \mathrm{K} \mathrm{p}_{\mathrm{O}}
$$

To do that here, we considered the numerical file $\mathrm{m}=\mathrm{f}(\mathrm{t})$, where $\mathrm{m}$ is the real mass gain (that also includes the first mass gain due to transient oxidation). For the lowest temperatures and near the end of experiment, the used thermobalance was not always accurate enough to detect the mass change between two successive weight measures (that were separated by only 40 seconds). Then it was decided to keep only one $\mathrm{m}$ value of ten to obtain a time step long enough to allow the measure of a more significant mass gain between two successive kept values. In addition, a great dispersion often remained among the kept successive values, a problem due to the lack of precision of the thermobalance again. In order to reduce the dispersion of the successive calculated derived numbers $\frac{\mathrm{dm}}{\mathrm{dt}}$, without loss of precision, each $\frac{\mathrm{dm}}{\mathrm{dt}}$ was estimated by the regression coefficient calculated on the interval of ten successive values of $\mathrm{m}$. Therefore the new time step is equal to ten times the measure time step (i.e. 400s). Thereafter the variation of $\mathrm{m} . \frac{\mathrm{dm}}{\mathrm{dt}}$ versus $-\mathrm{m}$ was plotted, the linearity of this curve was verified, then the values of $\mathrm{Kp}$ and $\mathrm{Kv}$ were determined.

In fact, $\mathrm{Kv}$ also includes the linear volatilization of the platinum thread to which hung the sample in the microbalance. It is the reason why this other contribution was separately determined for all temperatures with short thermogravimetry runs without any sample. Calculated by unit of area this contribution appeared, like it will be seen thereafter, as being almost negligible compared to chromia volatilization since its measured values were $0.93 \cdot 10^{-10}, 4.5 \cdot 10^{-10}, 26.3 \cdot 10^{-10}$ and $198 \cdot 10^{-10}$ g.s ${ }^{-1}$ for $1000,1100,1200$ and $1300^{\circ} \mathrm{C}$ respectively. However these values, after their conversion into mass loss by sample unit surface area $(0.42$, 2.2, 11.4 and $91 \cdot 10^{-10} \mathrm{~g} \cdot \mathrm{cm}^{-2} \cdot \mathrm{s}^{-1}$ ) were subtracted from the measured $\mathrm{Kv}$ values to give the final $\mathrm{Kv}$ constants. But the contribution of the platinum volatilization was neglected for the determination of the linear $\mathrm{K}_{1}$ constants.

\section{RESULTS}

\section{Metallographic Study of the As-cast Alloy and of the Oxidized Samples}

According to the Cr-Ni binary diagram, the alloy presents a single phase for all temperatures. The latter is Ni-austenite which contains the whole chromium in solid solution. The grain boundaries are not visible but it can be thought that the grain size of this alloy is about $25 \mu \mathrm{m}$, as observed on similar Ni-30Cr-xC ingots elaborated following the same way. The obtained chemical composition determined by EDS with the SEM is $70 \pm 0.5 \% \mathrm{w} \mathrm{Ni}$ and $30 \pm 0.5 \% \mathrm{w} \mathrm{Cr}$ (average value \pm standard deviation). The surface states of the alloy after 50 hours of oxidation for the four temperatures are illustrated by Fig. 1. The external oxide scale, exclusively of $\mathrm{Cr}_{2} \mathrm{O}_{3}$ (verified by EDS analysis on the parts of oxide that remained on samples), often left the alloy surface during the cooling after test, especially for the sample oxidized at $1000^{\circ} \mathrm{C}$. Voids also appeared in the subsurface over a depth that increases with temperature. The 20 to 30 measures led to the results that are summarized in Table I, in which the increasing of the oxide thickness with temperature can be seen. Two WDS chromium profiles (weight content) were performed from the extreme surface inwards the bulk for all samples (Fig. 2). The Cr-depletion depths logically increase with temperature, from about $40 \mu \mathrm{m}$ at $1000^{\circ} \mathrm{C}$ to ten times this value at $1300^{\circ} \mathrm{C}$. Lower the temperature is lower the minimal chromium content is.

\section{Thermogravimetry Results}

The four thermogravimetry curves obtained are shown in Fig. 3 (only the isothermal part of the mass gain curves). They are logically ordered following the order of the temperatures. Three of them show a global parabolic shape, but they also have a short first linear part with a great slope, except for $1300^{\circ} \mathrm{C}$ for what the parabolic oxidation was obviously already begun when the targeted temperature was reached. The $1100^{\circ} \mathrm{C}$ 
curve also shows a little jump corresponding to a local detachment of the chromia scale, probably due to compressive strains that developed during the oxide growth. Therefore the chromia scale was certainly fissured and allowed oxygen to directly access to the underlying alloy surface again. The little mass gain jump resulted from the local oxidation that became fast again.

The initial linear oxidation at the beginning of the isothermal step was first considered. The slope of the $\mathrm{m}=\mathrm{f}(\mathrm{t})$ straight lines for 1000,1100 and $1200^{\circ} \mathrm{C}$ was determined, from which the values of the $\mathrm{K}_{1}$ constants were deduced. For $1300^{\circ} \mathrm{C}$, the slope of the straight line tangential to the curve at the first point was taken as an approximate value of the slope of the previous (and unknown) linear oxidation part of the curve. All these values are displayed in the first line of Table II. In a $\ln \left(\mathrm{K}_{1}\right)=\mathrm{f}(1 / \mathrm{T})$ Arrhenius graph, it appears that the four points are relatively well aligned (Fig. 4). This means that first the beginning of the parabolic oxidation was very closed to the beginning of the isothermal $1300^{\circ} \mathrm{C}$ stage, then that the slope of the tangent to the curve can be taken as the $\mathrm{K}_{1}$ constant at $1300^{\circ} \mathrm{C}$. Second, this linear constant effectively obeys to an Arrhenius law, the activation energy of which was determined in the first line of Table III. Knowing the evolution of $\mathrm{K}_{1}$ with temperature, it was possible to calculate indirectly the mass gain before the beginning isothermal stage, according to equation (9). After having added the mass gain obtained during the isothermal linear oxidation (directly measured by the thermobalance), the total mass gain before parabolic oxidation is known for all temperatures (from $1.4 .10^{-5} \mathrm{~g} / \mathrm{cm}^{2}$ at $1000^{\circ} \mathrm{C}$ to $4.5 .10^{-4} \mathrm{~g} / \mathrm{cm}^{2}$ at $1300^{\circ} \mathrm{C}$ ).

The parabolic oxidation began when the external chromia scale became continuous all around the sample. Thereafter, the thermogravimetry data file can be exploited according to equation (22). This led to the four curves shown in Fig. 5 which presents the evolution of $m \cdot \frac{\mathrm{dm}}{\mathrm{dt}}$ versus $-\mathrm{m}$. These new curves first display a great dispersion of the points, notably at $1000^{\circ} \mathrm{C}$. But it fortunately becomes less marked when the temperature raises. This dispersion is due to the lack of precision of the thermobalance, especially at the lowest temperatures for which the mass gains between two consecutive measures are too close from one another. Despite of the calculation of the slope of the regression straight line for every ten time steps, a variation of the derived function, and of the $\mathrm{m} \cdot \frac{\mathrm{dm}}{\mathrm{dt}}$ values, is observed. Fortunately, this problem almost disappears when temperature increases, because of the faster oxidation and then the higher mass difference between two consecutive measures.

Nevertheless, for the three highest temperatures, a jump of the $\mathrm{m} \cdot \frac{\mathrm{dm}}{\mathrm{dt}}$ value can occur. For $1100^{\circ} \mathrm{C}$ it is clearly due to the little detachment which was already seen on the thermogravimetry curve in Fig. 3. For this curve it led to a particularly great jump, because of the mass gain itself but more because of the derived function (it is obvious when $\frac{\mathrm{dm}}{\mathrm{dt}}$ is plotted as a function of time). The jumps observed on the right of the $\mathrm{m} \cdot \frac{\mathrm{dm}}{\mathrm{dt}}$ curves for $1200^{\circ} \mathrm{C}$ and $1300^{\circ} \mathrm{C}$ (Fig. 5) are probably due to small detachments of the chromia scale or to another oxidation phenomenon. They can be not obvious on the thermogravimetry curves (Fig. 3) but $\frac{\mathrm{dm}}{\mathrm{dt}}$ is particularly sensitive to them. Indeed plotting the derived function versus time revealed that it effectively corresponds to a jump of $\frac{\mathrm{dm}}{\mathrm{dt}}$.

On the left of these jumps (i.e. for later times) the points are effectively almost aligned along a straight line. It is particularly true for the highest temperatures, while such an alignment is more difficult to observe for the lowest temperatures because of the greater dispersion of the points. Particularly at 1200 and at $1300^{\circ} \mathrm{C}$ the points are really aligned along the regression straight line calculated from them. In addition the latter is horizontal for $1000^{\circ} \mathrm{C}$ and shows a positive slope which is greater when temperature is greater. The deduced values of $\mathrm{Kp}$ and $\mathrm{Kv}$ are given in Table II, in which a value of $\mathrm{Kv}$ after correction from the platinum volatilization is also featuring. The two constants increase with temperature and the variation of their napierian logarithms versus the reciprocal temperature, shows that they follow an Arrhenius law (Fig. 6), the activation energies of which are given in Table III. 


\section{Comparison between Kv from Thermogravimetry and Microanalysis Results}

A balance sheet was made for chromium. $\mathrm{m}_{\mathrm{Cr}}^{\text {bulk }}$, the amount of total chromium mass per unit surface area that left the bulk to diffuse towards the oxidation front, was assessed for the four temperatures. It was determined according to equation (23). In fact an approximate value was calculated according to (24).

$$
\mathrm{m}_{\mathrm{Cr}}^{\text {bulk }}=\rho \cdot \int_{0}^{\mathrm{dd}}\left[\%_{\mathrm{w}} \mathrm{Cr}(\text { bulk })-\%_{\mathrm{w}} \mathrm{Cr}(\mathrm{e})\right] . \mathrm{de} \quad(23) \quad \mathrm{m}_{\mathrm{Cr}}^{\text {bulk }} \cong \rho \cdot \Delta \mathrm{e} \cdot \sum_{\mathrm{n}=1}^{\mathrm{N}}\left[\%_{\mathrm{w}} \mathrm{Cr}(\text { bulk })-\%_{\mathrm{w}} \mathrm{Cr}_{\mathrm{n}}\right]
$$

where $\rho$ is the density of the alloy $\left(8.2 \mathrm{~g} . \mathrm{cm}^{-3}\right.$ assessed by the ratio of the mass of a $5 * 5 * 5 \mathrm{~mm}^{3}$ cube by its volume), $\%_{\mathrm{w}} \mathrm{Cr}$ (bulk) is the weight chromium content in the bulk, $\%_{\mathrm{w}} \mathrm{Cr}(\mathrm{e})$ is the weight chromium content at the depth e from the extreme surface, $\%_{\mathrm{w}} \mathrm{Cr}_{\mathrm{n}}$ is the weight chromium content at the depth $\mathrm{n} . \Delta \mathrm{e}$ from the extreme surface, and $\mathrm{N}$ is the entire value of the ratio of the chromium depletion depth (dd) by the step $\Delta \mathrm{e}$.

$\mathrm{m}_{\mathrm{Cr}}^{\text {bulk }}$ is to be compared to the sum of two terms. The first one, $\mathrm{m}_{\mathrm{Cr}}^{\text {scale }}$, is the chromium quantity contained in the chromia scale, which was assessed on the parts of this scale that remained on the sample after test. The second one, $\mathrm{m}_{\mathrm{Cr}}^{\mathrm{vol}}$, is the chromium quantity that left the sample with the volatile $\mathrm{CrO}_{3}$ form.

The chromium quantity per unit surface area contained in the chromia scale can be calculated according to the equation (25) from the chromia thicknesses $\mathrm{e}_{\mathrm{Cr}_{2} \mathrm{O}_{3}}$ (Table I), its density $\rho_{\mathrm{Cr}_{2} \mathrm{O}_{3}}\left(5.2 \mathrm{~g} . \mathrm{cm}^{-3}\right)$ and the molar weights of $\mathrm{Cr}$ and $\mathrm{Cr}_{2} \mathrm{O}_{3}$. The chromium quantity gone away by volatilization is determined by equation (26).

$$
\mathrm{m}_{\mathrm{Cr}}^{\text {scale }}=\rho_{\mathrm{Cr}_{2} \mathrm{O}_{3}} \cdot\left(\frac{2 \cdot \mathrm{M}_{\mathrm{Cr}}}{\mathrm{M}_{\mathrm{Cr}_{2} \mathrm{O}_{3}}}\right) \cdot \mathrm{e}_{\mathrm{Cr}_{2} \mathrm{O}_{3}} \quad \text { (25) } \quad \mathrm{m}_{\mathrm{Cr}}^{\mathrm{vol}}=\mathrm{Kv}_{\mathrm{Cr}} \cdot \Delta \mathrm{t}=\frac{2 \mathrm{M}_{\mathrm{Cr}}}{\mathrm{M}_{\mathrm{Cr} 2 \mathrm{O} 3}} \cdot \mathrm{Kv} \cdot \Delta \mathrm{t}=0.684 \mathrm{Kv} \cdot \Delta \mathrm{t}
$$

where $\Delta \mathrm{t}$ is the test duration (180,000 seconds).

Table IV shows all these values and it appears that there is for $1000^{\circ} \mathrm{C}$ a very good correspondence between the chromium mass that left the alloy $\left(\mathrm{m}_{\mathrm{Cr}}^{\text {bulk }}\right)$ and the sum of chromium present in $\mathrm{the} \mathrm{Cr}_{2} \mathrm{O}_{3} \mathrm{scale}$ $\left(\mathrm{m}_{\mathrm{Cr}}^{\text {scale }}\right)$ and chromium that disappeared in volatile $\mathrm{CrO}_{3}\left(\mathrm{~m}_{\mathrm{Cr}}^{\mathrm{vol}}\right)$. For 1100 and $1200^{\circ} \mathrm{C}$ the correspondence is relatively good too: the values of $\mathrm{m}_{\mathrm{Cr}}^{\text {scale }}+\mathrm{m}_{\mathrm{Cr}}^{\mathrm{vol}}$ are lower than $\mathrm{m}_{\mathrm{Cr}}^{\text {bulk }}$ but remain close to the latter. On the contrary, for $1300^{\circ} \mathrm{C}, \mathrm{m}_{\mathrm{Cr}}^{\text {scale }}+\mathrm{m}_{\mathrm{Cr}}^{\mathrm{vol}}$ is significantly lower than $\mathrm{m}_{\mathrm{Cr}}^{\text {bulk }}$ but this difference can be explained. Indeed, the chromium depletion is sufficiently deep to lead to a not really correct calculation of $\mathrm{m}_{\mathrm{Cr}}^{\text {bulk }}$ in the zones that are near a ridge or a corner of the parallelepiped sample.

\section{DISCUSSION}

The linearity observed for the curves finally obtained for the second part of the curves displayed in Fig.5, clearly indicates that $\mathrm{m}$ and its derived function $\frac{\mathrm{dm}}{\mathrm{dt}}$ effectively obey the equation (22) (in which the term $\mathrm{Kp}$ is supposed constant). Then it was always possible to extract from the curve the values of both $\mathrm{Kp}$ and $\mathrm{Kv}$ for the four tested temperatures. Their comparison with constants reported in previous works show a good agreement with the latter. The Kv values obtained here were first confirmed by the chromium balance sheets, notably for the three lowest temperatures. Second, they are in good agreement with the volatilization constants reported by other authors in Table V. The values of Kp, displayed in Table II, are of the same order of magnitude as most of $\mathrm{Kp}$ values obtained for the same temperatures with other chromia-forming alloys, nickel base or cobalt base.

In order to verify the accuracy of the determination of both the parabolic constant $\mathrm{Kp}$ and the volatilization constant $\mathrm{Kv}$, each theoretic (or mathematical) curve was plotted together with the real curve measured by thermogravimetry for the same temperature (Fig. 7). The mathematical curves were drawn from the equation (22) by calculating for each step the new elementary mass gain according to equation (27) in which each elementary mass gain $(d m)_{n+1}$, obtained between $t=n \cdot d t$ and $t=(n+1)$.dt, is determined from the previous total mass gain $\mathrm{m}_{\mathrm{n}}$, the two constants $\mathrm{Kp}$ and $\mathrm{Kv}$ previously determined, and the time step dt (40 seconds too). 


$$
(\mathrm{dm})_{\mathrm{n}+1}=\frac{\mathrm{Kp}}{\mathrm{m}_{\mathrm{n}}} \cdot \mathrm{dt}-\mathrm{Kv} \cdot \mathrm{dt}
$$

The experimental initial mass gain that already existed at $\mathrm{t}=0$ (due to the transient oxidation) was taken for the first step to avoid an initial division by zero, but it was subtracted thereafter from the whole mathematical curve. It appears in Fig. 7 that the mathematical curves correctly fit the experimental ones, notably on their second part, with notably a good "parallelism" between the ends of the two curves, which is on a great importance for long times predictions. At the opposite, the fit can be a little worse for the first half of the curves, in which some experimental curves presented small defects essentially due to a little detachment of the chromia scale, or in which the expression of Kp is not yet almost constant.

\section{CONCLUSION}

The parabolic constant $\mathrm{Kp}$ and the volatilization constant $\mathrm{Kv}$, respectively corresponding to the Wagner's law type part of the mass gain kinetic and to the vaporization of chromia into volatile $\mathrm{CrO}_{3}$ when temperature is higher than $1000^{\circ} \mathrm{C}$, were here determined together for a simple binary $\mathrm{Ni}-30 \mathrm{Cr}$ alloy for the $1000-1300^{\circ} \mathrm{C}$ temperature range, with notably a good agreement with previous results about the volatilization rate of chromia. This procedure, that appeared well adapted for this very simple alloy, allows to extract from classical thermogravimetry files, these two kinetic constants that are both of a great importance to wholly characterize the deterioration of a chromia-forming alloy by oxidation at very high temperatures. But it is possible that it becomes less true for more complex chromia-forming alloys or superalloys since these ones usually also contain other very oxidable elements that can significantly participate to the mass gain without corresponding to the model used here.

\section{ACKNOWLEDGMENTS}

The author thanks Lionel Aranda who performed the thermogravimetry tests, and the Microanalysis Common Service of the Faculty of Science of Nancy, especially Johann Ravaux and Alain Kohler. 


\section{REFERENCES}

1. $\quad$ P. Kofstad, High Temperature Corrosion, Elsevier applied science, 1988.

2. J. Di Martino, C. Rapin, P. Berthod, R. Podor, and P. Steinmetz, Corrosion Science, 46, 1849-1864 (2004)

3. J. Di Martino, C. Rapin, P. Berthod, R. Podor, and P. Steinmetz, Corrosion Science, 46, 1865-1881 (2004)

4. $\quad$ C. T. Sims and W. C. Hagel, The Superalloys, John Wiley \& Sons, 1972.

5. $\quad$ E. F. Bradley, Superalloys : A Technical Guide, ASM International, 1988.

6. W.J. Quadakkers, J. Piron-Abellan, and V. Shemet, Materials Research, 7(1), 203-208 (2004)

7. Oishi N., and Yamazaki Y., Proceedings (SOFC IV) -Electrochemical Society, 99-19, 759-766 (1999)

8. Kim Y.-W., and Belton G.R., Metallurgical Transactions, 5, 1811-1816 (1974)

9. Hagel W.C., Transactions of the ASM, 56, 583-599 (1963)

10. Tedmon C.S. Jr, Journal of the Electrochemical Society, 113(8), 766-768 (1966)

11. Graham H.C., Davis H.H., Journal of the American Ceramic Society, 54(2), 89-93 (1971)

12. J. Di Martino, Oxydation à haute temperature et corrosion par le verre $C 3$ de superalliages base cobalt, PhD Thesis, University Henri Poincaré Nancy 1 France, 2002.

13. C.A. Stearns, F.J. Kohl, and G.C. Fryburg, Journal of the Electrochemical Society, 121(7), 945-951 (1974) 
Table I. Thicknesses of the external chromia scale after the thermogravimetric tests

\begin{tabular}{|c|c|c|c|c|}
\hline \multirow{2}{*}{$\begin{array}{c}\text { Thickness of the external } \\
\mathbf{C r}_{2} \mathbf{O}_{3} \text { oxide layer }\end{array}$} & $\mathbf{1 0 0 0}^{\circ} \mathbf{C}$ & $\mathbf{1 1 0 0}^{\circ} \mathbf{C}$ & $\mathbf{1 2 0 0}^{\circ} \mathbf{C}$ & $\mathbf{1 3 0 0}^{\circ} \mathbf{C}$ \\
\cline { 2 - 5 } & $\mathbf{6 . 3 8}$ & $\mathbf{1 2 . 4 6}$ & $\mathbf{2 2 . 9 0}$ & $\mathbf{3 8 . 9 5}$ \\
\hline Average thickness & 1.08 & 1.34 & 1.23 & 3.11 \\
\hline
\end{tabular}

Table II. Values obtained for the transient linear oxidation constant $\mathrm{K}_{\mathrm{l}}$, the parabolic constant $\mathrm{Kp}$ and the volatilization constant $\mathrm{Kv}$

\begin{tabular}{|c|c|c|c|c|}
\hline Oxidation constants & $1000^{\circ} \mathrm{C}$ & $1100^{\circ} \mathrm{C}$ & ${ }_{1200}^{\circ} \mathrm{C}$ & $1300^{\circ} \mathrm{C}$ \\
\hline $\begin{array}{l}\text { Value of the } K_{1} \text { constant } \\
\left(\mathrm{g} / \mathrm{cm}^{2} / \mathrm{s}\right)\end{array}$ & $5.1 \cdot 10^{-8}$ & $18 \cdot 10^{-8}$ & $30.10^{-8}$ & $125.10^{-8}$ \\
\hline $\begin{array}{l}\text { Value of the Kp constant } \\
\qquad\left(\mathrm{g}^{2} \cdot \mathrm{cm}^{-4} \cdot \mathrm{s}^{-1}\right)\end{array}$ & $2.8 \cdot 10^{-12}$ & $23 \cdot 10^{-12}$ & $67 \cdot 10^{-12}$ & $245 \cdot 10^{-12}$ \\
\hline $\begin{array}{l}\text { Value of the } \mathrm{Kv} \text { constant } \\
\qquad\left(\mathrm{g} \cdot \mathrm{cm}^{-2} \cdot \mathrm{s}^{-1}\right)\end{array}$ & $1.3 \cdot 10^{-10}$ & $89 \cdot 10^{-10}$ & $168 \cdot 10^{-10}$ & $367 \cdot 10^{-10}$ \\
\hline $\begin{array}{l}\text { Value of the } \mathbf{K v} \text { constant } \\
\left(\mathbf{g ~ c . ~}^{-2} \cdot \mathbf{s}^{-1}\right) \\
\text { corrected from Pt volatilization }\end{array}$ & $0.9 \cdot 10^{-10}$ & $87.10^{-10}$ & $157.10^{-10}$ & $276 \cdot 10^{-10}$ \\
\hline
\end{tabular}

Table III. Activation energies for the three types of oxidation constants, calculated from the results obtained for the four temperatures (*except $1000^{\circ} \mathrm{C}$ for $\mathrm{Kv}$ )

\begin{tabular}{|c|c|}
\hline Oxidation constants & $\begin{array}{c}\text { Activation energy } \\
\mathbf{k J} / \mathbf{m o l}\end{array}$ \\
\hline $\mathrm{K}_{1}$ & 167 \\
\hline $\mathrm{Kp}$ & 242 \\
\hline $\mathrm{Kv}$ & $104^{*}$ \\
\hline
\end{tabular}


Table IV. Chromium balance sheet between the chromium quantity lost by the alloy, chromium present in the remaining chromia scale and chromium lost volatilization

\begin{tabular}{|c|c|c|c|c|}
\hline chromium quantities $\left(\mathrm{mg} / \mathrm{cm}^{2}\right)$ & $1000^{\circ} \mathrm{C}$ & $1100^{\circ} \mathrm{C}$ & $1200^{\circ} \mathrm{C}$ & $1300^{\circ} \mathrm{C}$ \\
\hline still present in the chromia scale & 2.27 & 4.43 & 8.15 & 13.9 \\
\hline lost by vaporization of chromia into $\mathrm{CrO}_{3}$ & 0.01 & 1.07 & 1.93 & 3.40 \\
\hline sum of the two upper lines & 2.28 & 5.50 & 10.1 & 17.3 \\
\hline $\begin{array}{l}\text { chromium having left the alloy } \\
\text { (calculated on the two Cr WDS profiles) }\end{array}$ & 2.22 to 2.28 & 8.10 to 9.13 & 12.7 to 12.9 & 27.3 to 31.5 \\
\hline
\end{tabular}

Table V. Comparison of the obtained volatilization constants with those reported in previous works

\begin{tabular}{|c|c|c|c|}
\hline $\begin{array}{c}\mathbf{K v} \\
\left(10^{-10}{\left.\mathrm{~g} . \mathrm{cm}^{-2} \cdot \mathrm{s}^{-1}\right)}^{*}\right.\end{array}$ & $1100^{\circ} \mathrm{C}$ & $1200^{\circ} \mathrm{C}$ & $1300^{\circ} \mathrm{C}$ \\
\hline $\begin{array}{c}\text { Hagel (9) } \\
\mathrm{Cr}_{2} \mathrm{O}_{3}+1 \% \mathrm{Y}_{2} \mathrm{O}_{3} \\
76 \mathrm{mmHg} \mathrm{O}\end{array}$ & 37 & 124 & 360 \\
\hline $\begin{array}{c}\text { Stearns et al (13) } \\
\text { Preoxidized Cr } \\
0.115 \text { Torr } \mathrm{O}_{2}\end{array}$ & 83 & 280 & $/$ \\
\hline $\begin{array}{c}\text { Di Martino (12) } \\
\text { Co base superalloys } \\
0.2 \text { atm } \mathrm{O}_{2}\end{array}$ & 2.3 & 45 & $/$ \\
\hline This study & $\mathbf{8 7}$ & $\mathbf{1 5 7}$ & $\mathbf{2 7 6}$ \\
\hline
\end{tabular}

* : calculated from the $\mathrm{Kv}=0.214 . \exp \left(-204 \mathrm{~kJ} \cdot \mathrm{mol}^{-1} / \mathrm{R} . \mathrm{T}\right)$ formula 

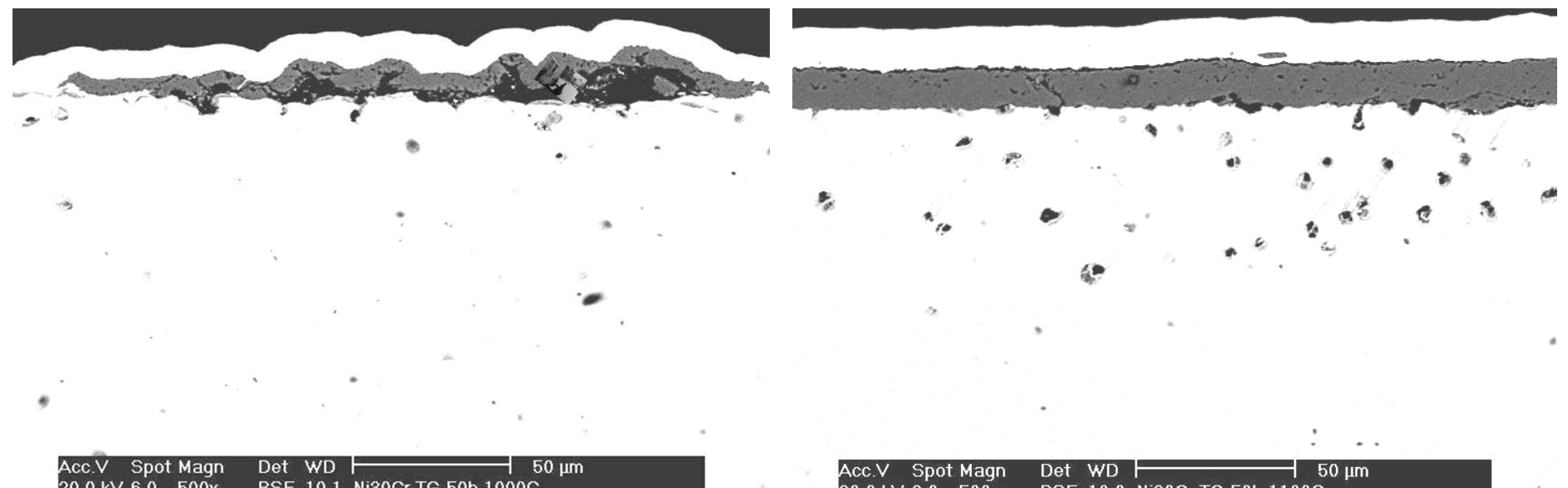

after 50 hours at $1000^{\circ} \mathrm{C}$

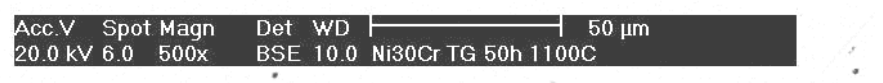

after 50 hours at $1100^{\circ} \mathrm{C}$
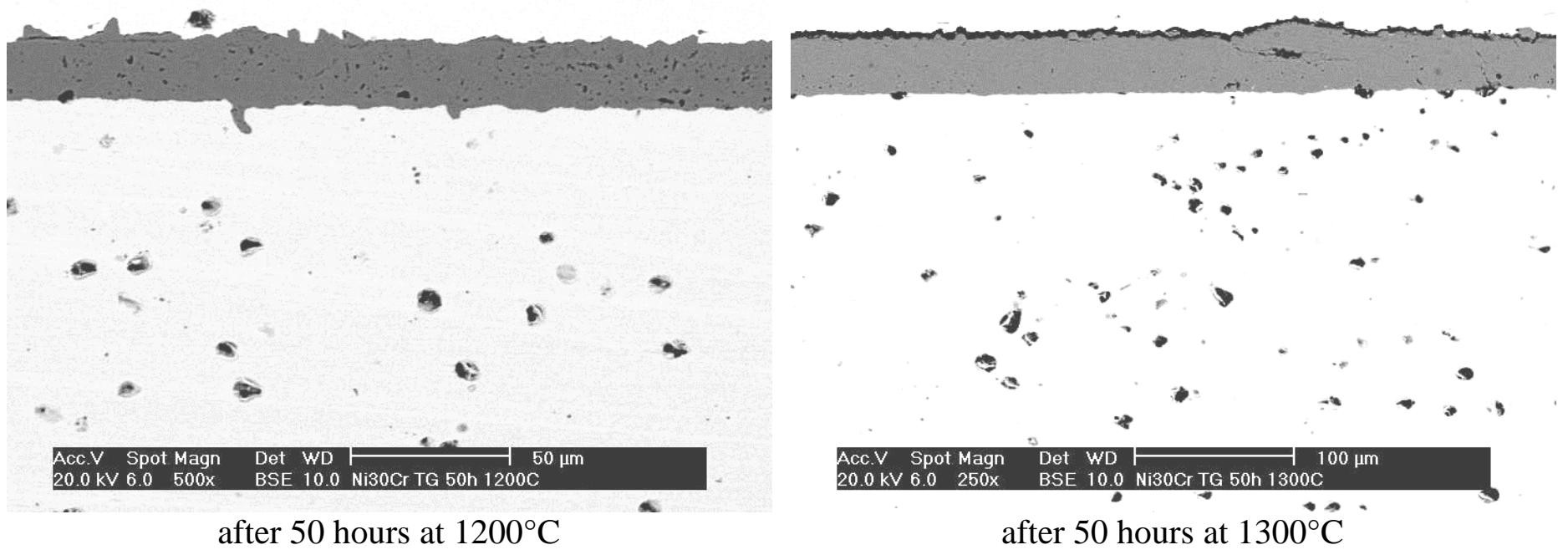

Fig. 1. Surface and sub-surface states of the samples after oxidation at $1000^{\circ} \mathrm{C}, 1100^{\circ} \mathrm{C}, 1200^{\circ} \mathrm{C}$ and $1300^{\circ} \mathrm{C}$ 



Fig. 2. Profiles of chromium weight contents for the four temperatures $1000^{\circ} \mathrm{C}, 1100^{\circ} \mathrm{C}, 1200^{\circ} \mathrm{C}$ and $1300^{\circ} \mathrm{C}$


Fig. 3. The obtained thermogravimetry curves 


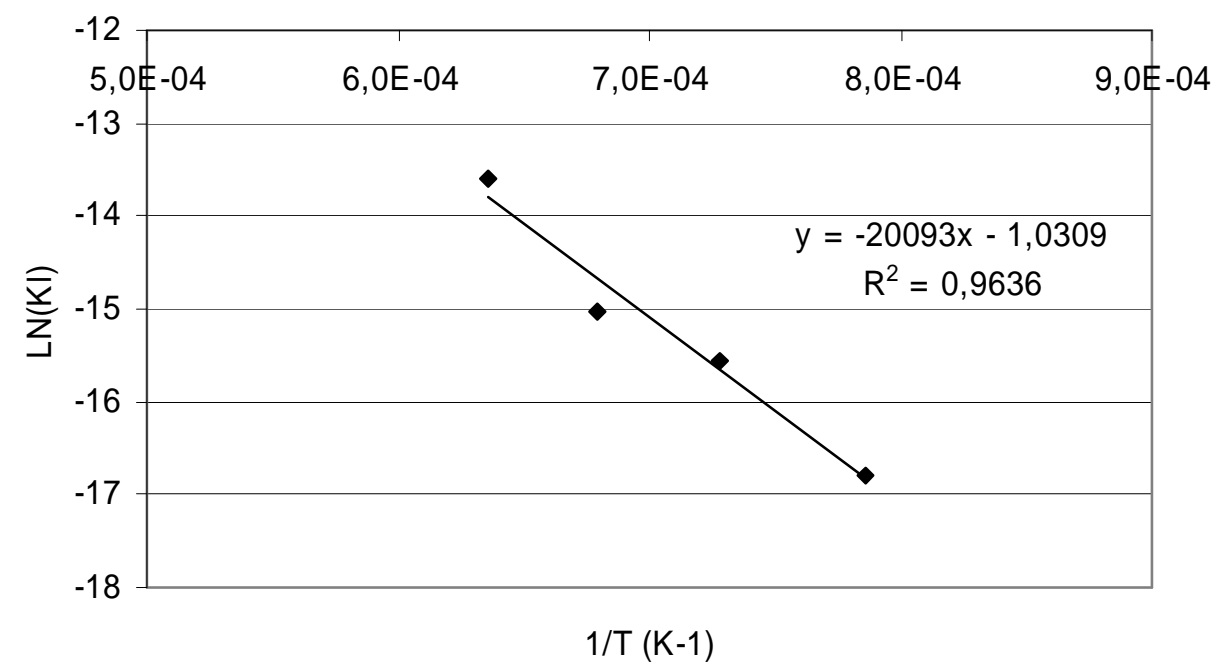

Fig. 4. Linear oxidation constant (corresponding to the transient oxidation) versus temperature in an Arrhenius graph


Fig. 5. $m \cdot \frac{\mathrm{dm}}{\mathrm{dt}}$ plotted versus $-\mathrm{m}$ for the four temperatures 

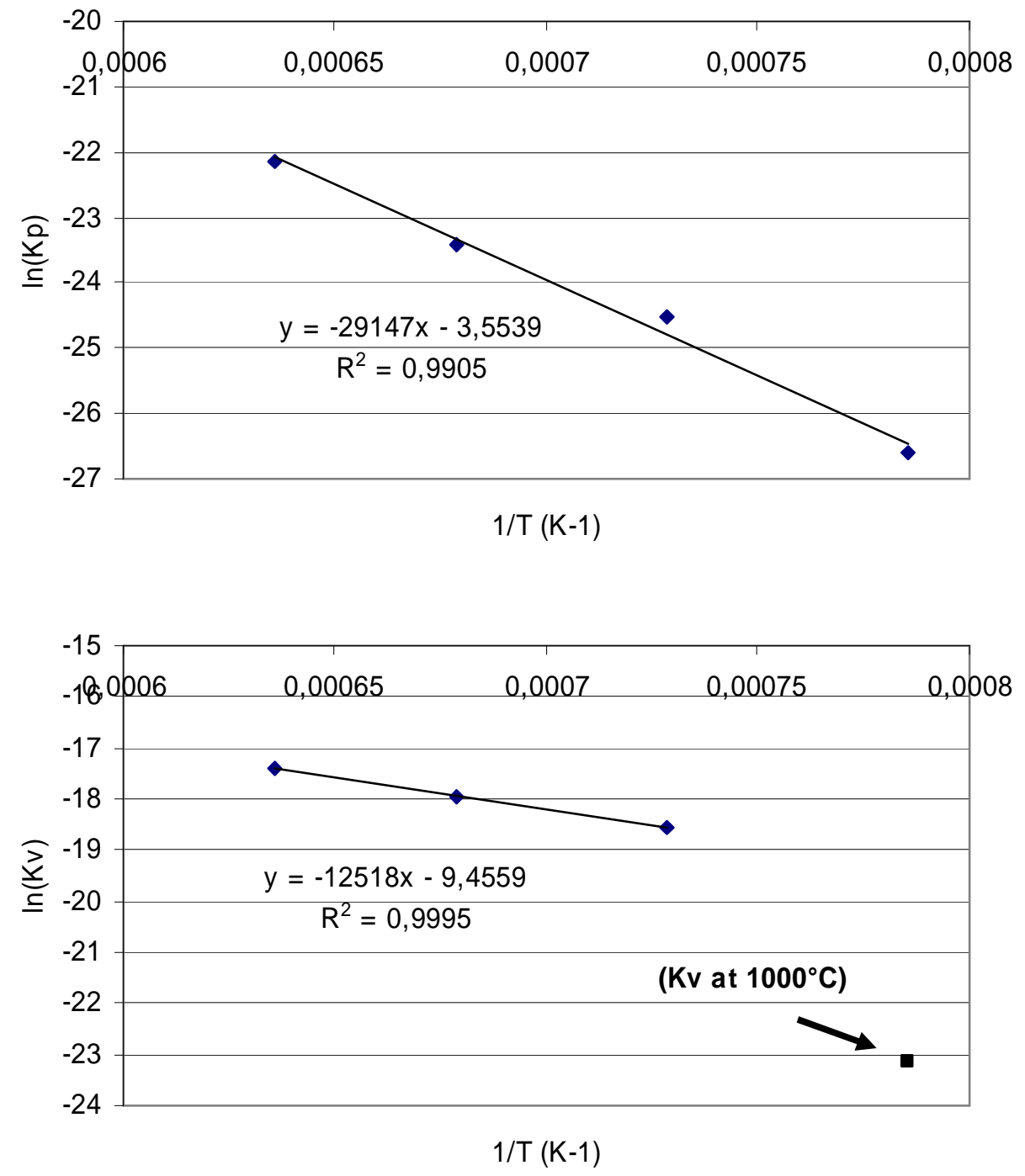

Fig. 6. Variation of the $\mathrm{Kp}$ and $\mathrm{Kv}$ measured values versus the temperature in an Arrhenius plotting 

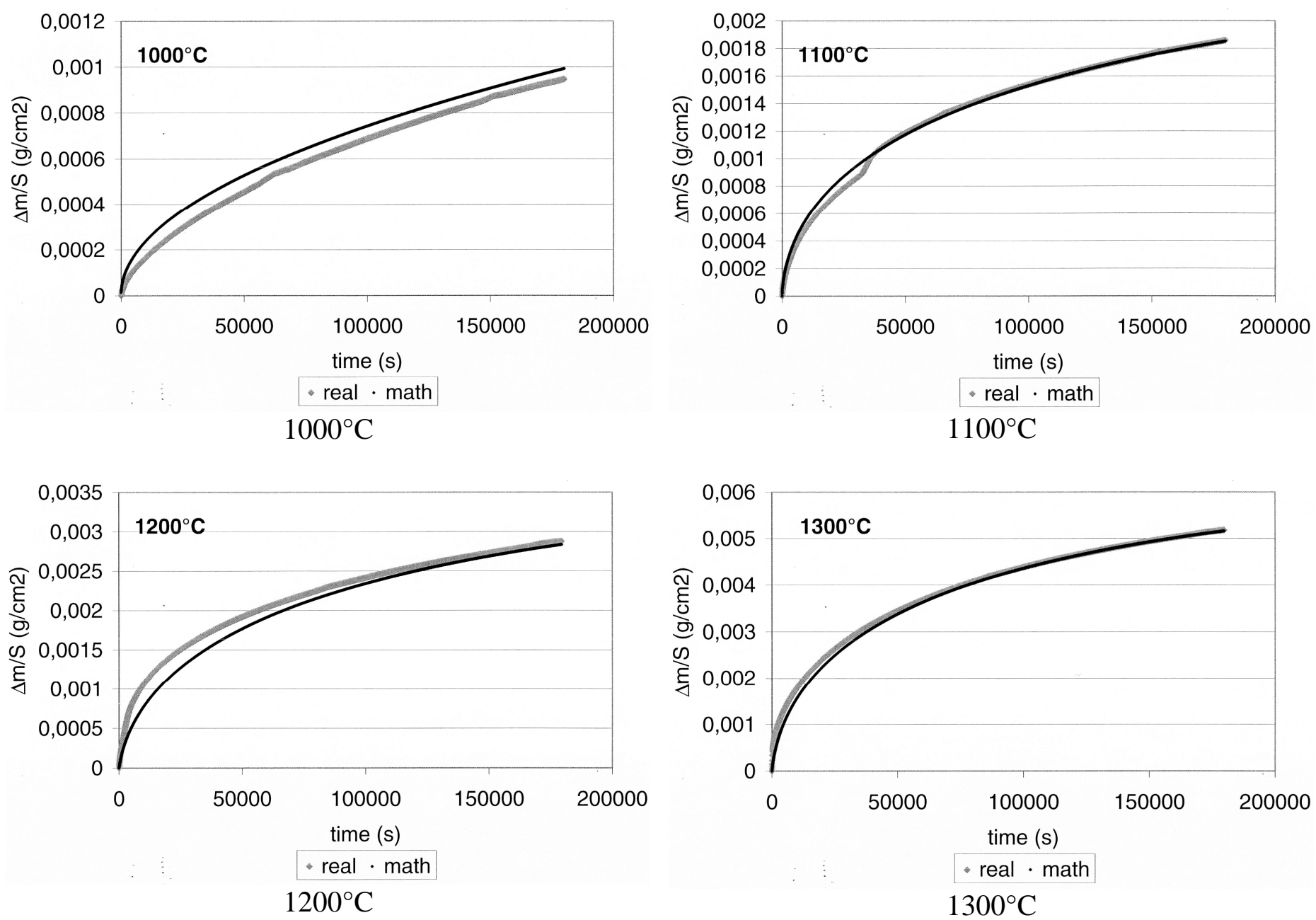

Fig. 7. Thermogravimetry curves: theoretic (in gray) and experimental (in black) 